
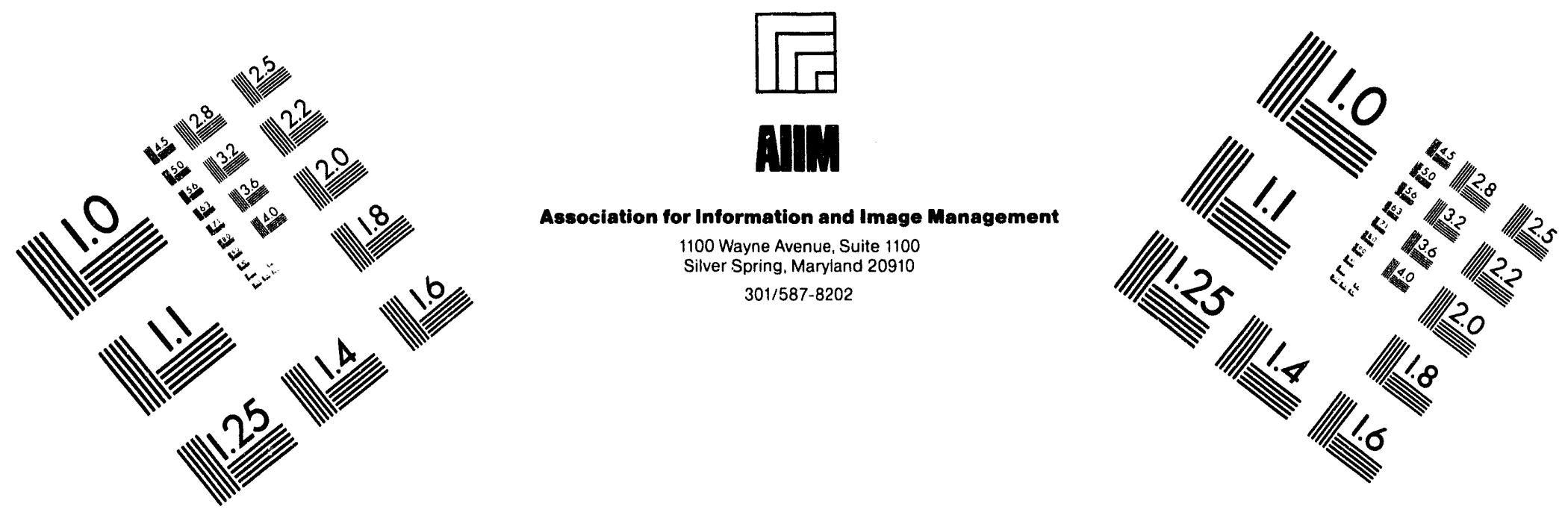

\title{
Centimeter
}

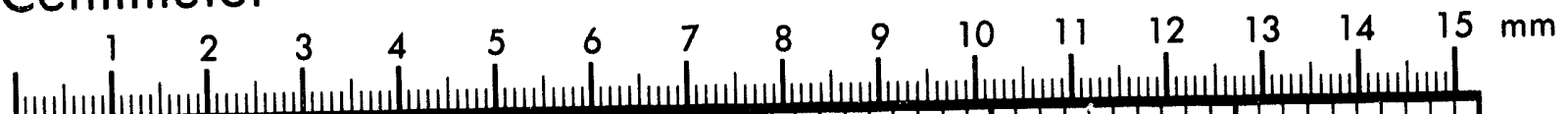
| Inches
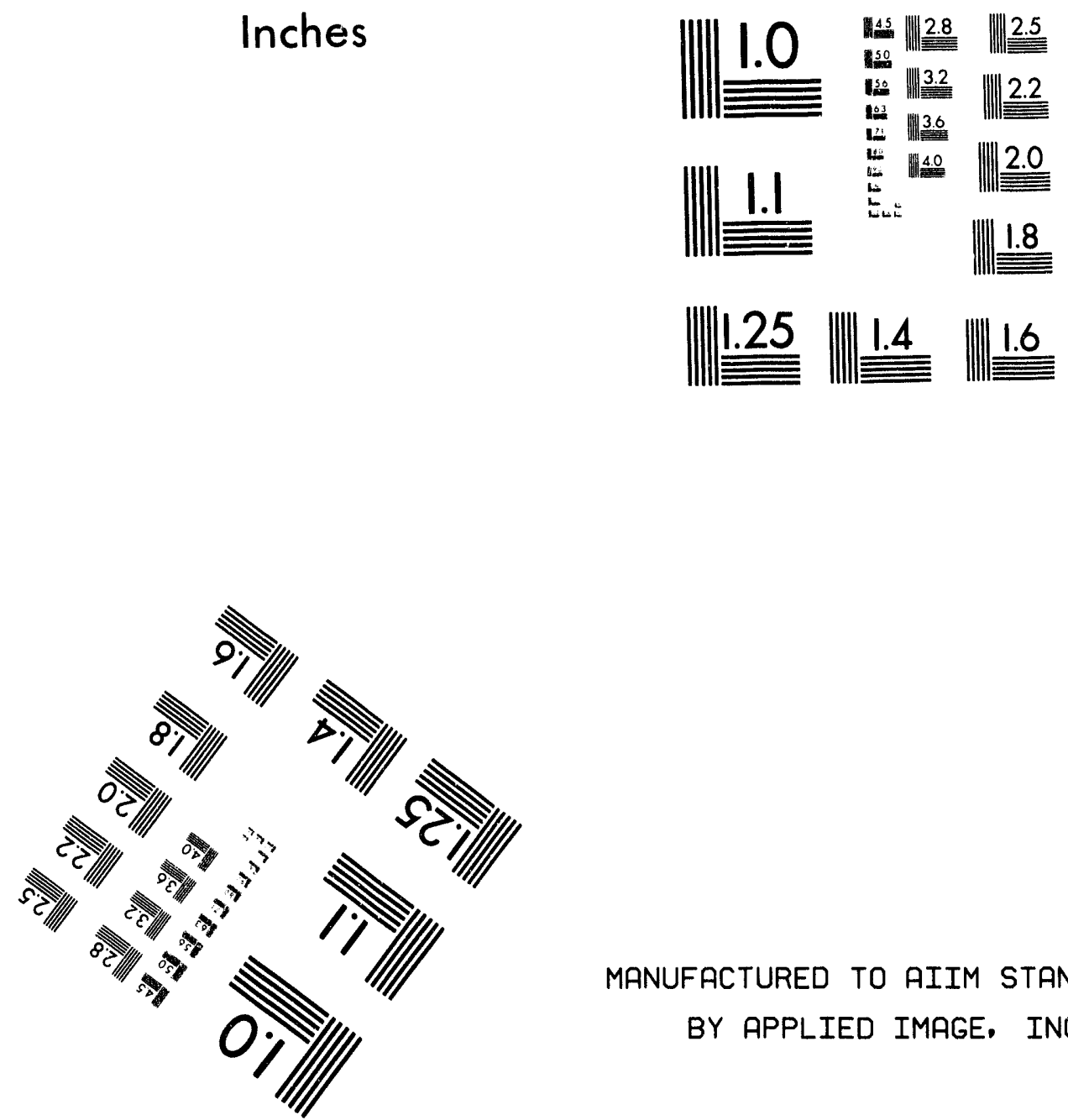

MANUFACTURED TO AIIM STANDARDS

BY APPLIED IMAGE, INC.

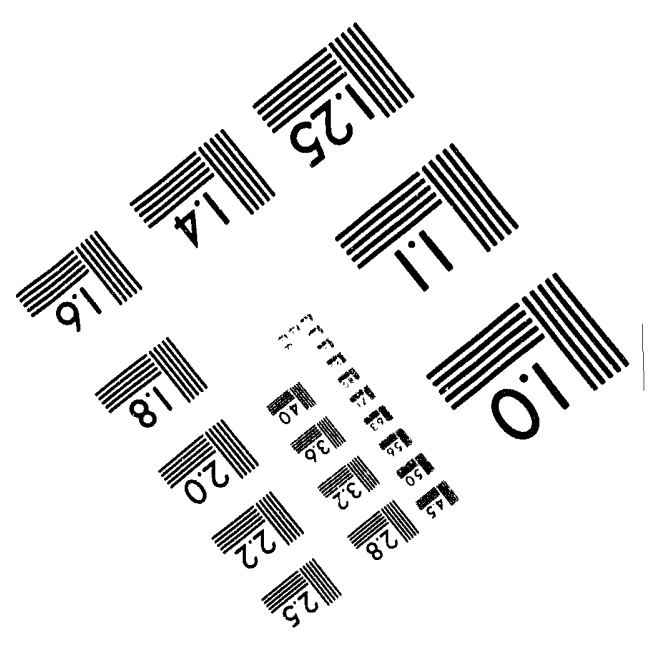



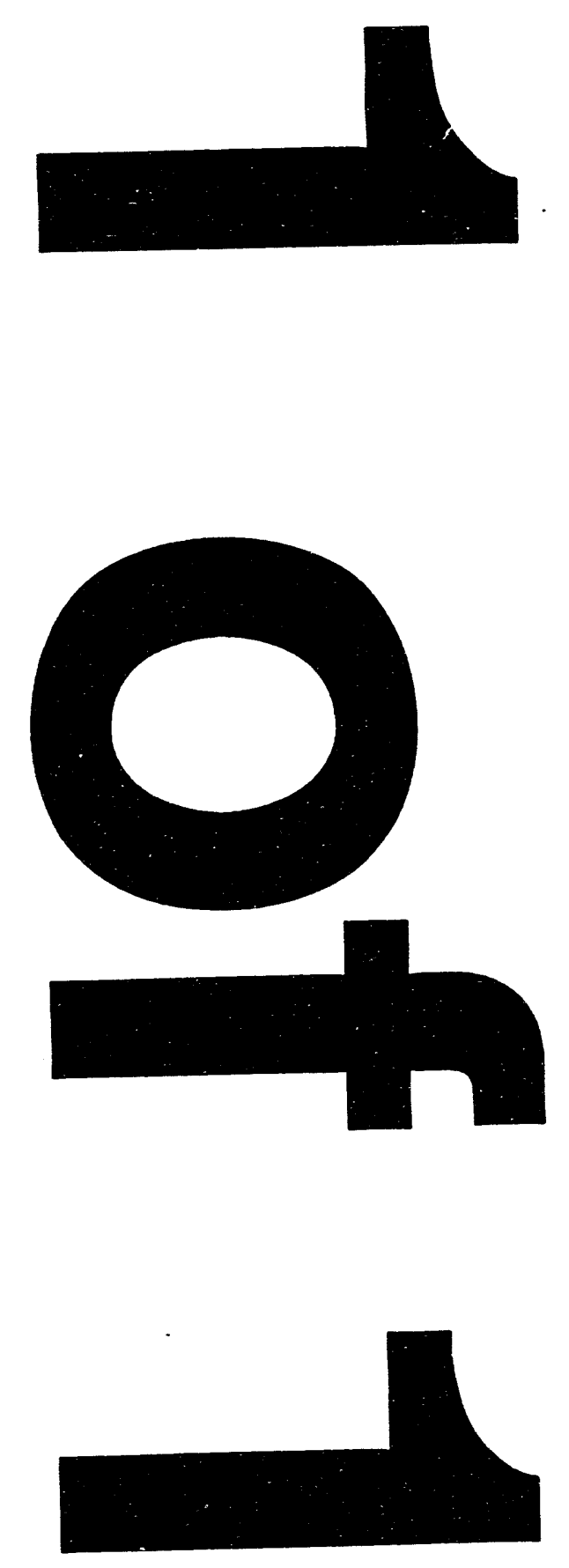


\title{
Conf-940401--6
}

UCRL-JC-115229

PREPRINT

\section{Neutron Interrogation to Identify Chemical Elements with an Ion-Tube Neutron Source (INS)}

\author{
R. A. Alvarez \\ A. D. Dougan \\ M. R. Rowland \\ T. F. Wang
}

This paper was prepared for submittal to the Methods and Applications of Radioanalytical Chemistry-III

Kailua-Kona, Hawaii

April 10-16, 1994

April 7, 1994

This is a preprint of a paper intended for publication in a journal or proceedings. Since changes may be made before publication, this preprint is made available with the 4 understanding that it will not be cited or reproduced without the permission of the author.

\section{MASTR?}

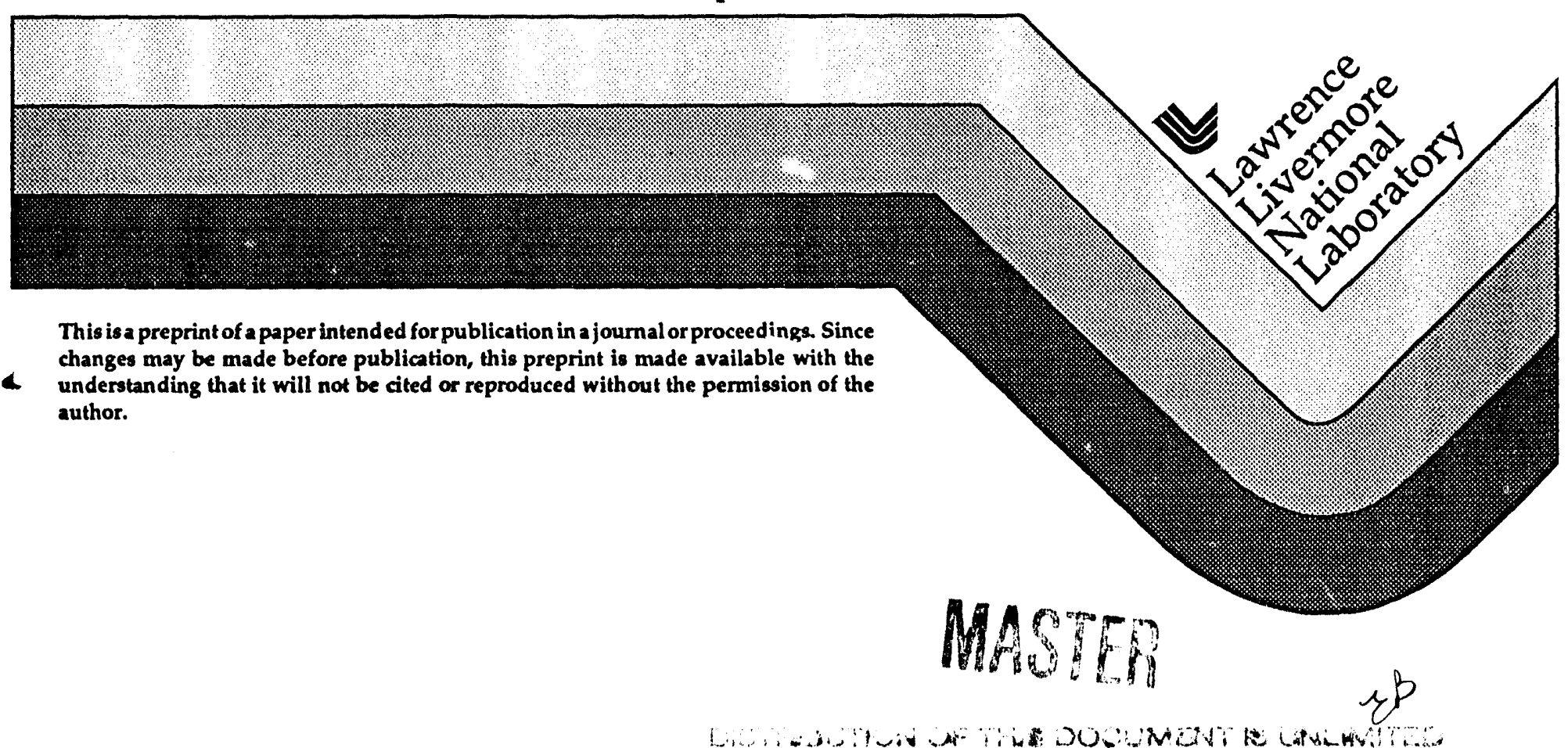




\section{DISCLAIMER}

This document was prepared as an account of work sponsored by an agency of the United States Govermment. Neither the United States Government nor the University of California nor any of their employees, makes any warranty, express or implied, or assumes any legal liability or responsibility for the accuracy, completeness, or usefulness of any information, apparatus, product, or process disclosed, or represents that its use would not infringe privately owned rights. Reference herein to any specific commercial products, process, or service by trade name, trademark, manufactarer, or otherwise, does not necessarily constitute or imply its endorsement, recommendation, or favoring by the United States Government or the University of California The views and opinions of authors expressed herein do not necessarily state or reflect those of the United States Govcrnment or the University of Califomia, and shall not be used for advertising or product endorsement purposes. 


\title{
Neutron Interrogation to Identify Chemical Elements with an Ion-Tube Neutron Source (INS)*
}

\author{
R. A. Alvarez, A. D. Dougan, M. R. Rowland, and T. F. Wang, \\ Lawrence Livermore National Laboratory \\ Livermore, CA
}

\section{Abstract}

A non-destructive analysis technique using a portable, electric ion-tube neutron source (INS) and gamma ray detector has been used to identify the key constituent elements in a number of sealed munitions, and from the elemental makeup, infer the types of agent within each. The high energy (14 $\mathrm{MeV}$ ) and pulsed character of the neutron flux from an INS provide a method of measuring, quantitatively, the oxygen, carbon, and fluorine content of materials in closed containers, as well as the other constituents that can be measured with low-energy neutron probes. The broad range of elements that can be quantitatively measured with INS-based instruments provides a capability of verifying common munition fills; it provides the greatest specificity of any portable neutron-based technique for determining the full matrix of chemical elements in completely unrestricted sample scenarios. The specific capability of quantifying the carbon and oxygen content of materials should lead to a fast screening technique which, can discriminate very quickly between high-explosive and chemical agent-filled containers.

\footnotetext{
${ }^{*}$ Work performed under the auspices of the U.S. Department of Energy by the Lawrence Livermore National Laboratory under Contract $\mathrm{W}-7405-$ Eng-48.
} 


\section{INTRODUCTION}

Neutron interrogation to identify chemical elements makes use of the characteristic gamma rays emitted by atomic nuclei when these penetrating, uncharged particles interact with the nuclei. The energy spectrum, and/or the temporal character of the gamma-ray emissions, is usually uni gue for each type of atom. These gamma-rays from the bombarded target sample can be used to identify, nondestructively, the atomic elements present. By applying the appropriate spectral peak fitting techniques it is possible to infer, quantitatively, the atomic ratios for the target material.

Table I shows the atomic composition of several explosives 1 and chemical agents ${ }^{2}$. In the case of high explosives ( $\mathrm{HE}$ ) and chemical weapons ( $\mathrm{CW}$ ), the quantitative ratios of the common constituents of organic materials, oxygen, carbon, and hydrogen, are sufficiently different to distinguish between these two classes. Other more "exotic" elements are also present in these materials: relatively high concentrations of nitrogen in the explosives; and chlorine, sulfur, phosphorous, fluorine, and arsenic, as well as nitrogen, in differing amounts, in each of the $\mathrm{CW}$ agents. Identification of the combinations of these elements in a sample is adequate not only to distinguish the $\mathrm{CW}$ materials from high explosives, but also to distinguish the $\mathrm{CW}$ agents from one another. For each of these elements there is one or more type of neutron interaction that generates one or more characteristic gamma-rays that can be used for identification.

The measurements reported here utilized an ion-tube neutron source (INS), together with a high-purity germanium (HPGe) gamma-ray detector to identify the contents of several types of munitions and storage containers at Tooele Army Depot, Utah during approximately two weeks of measurements in August, 1992. Other methods using neutron interrogation have 
been used ${ }^{3}$ to non-destructively assay $\mathrm{CW}$ ayents and $\mathrm{HE}$ munitions, such as the use of a californiurn-252. fission source 4 or an associated particle sealed-tube neutron generator source ${ }^{5}$.

\section{EQUIPMENTAL METHOD}

A simplified block diagram for the experimental apparatus is shown in Fig. 1. The INS and a HPGe gamma-ray detector were placed adjacent to the target sample. For most measurements a "shadow shield" of lead, typically 8 inches thick, was placed between the neutron source and the detector to reduce the direct flux of neutrons from the source striking the detector. We used a sealed tube neutron generator with a yield of $10^{3}-10^{4} 14.1 \mathrm{MeV}$ neutrons/pulse. The pulse repetition rates were operated at 5,000 and 10,000 $\mathrm{Hz}$. The gamma-ray detector was an ORTEC $45 \% \mathrm{~N}$-type, which was mounted in an all-attitude cryostat for portability. An NE213 liquid scintillator was used as a neutron flux monitor. For most measurements, the neutron source, shadow shield, gamma-ray detector, and neutron monitor were maintained in a fixed geometry in a wooden jig. In a few measurements the source and detector were positioned on opposite sides of the target, which, in effect, replaced the shadow shield.

The amplifier output of the HPGe signals was fed to two pulse-height analyzers (PHA) which were on cards in the data acquisition computer. Another card in the computer - a multichannel arbitrary waveform generator - was programmed to generate independent time gates for the two PHAs, as well as the drive pulses for the neutron generator. The measurement duration, gate widths, PRF, and appropriate delay times between the neutron drive pulse and the two PHA gate pulses, were software controlled.

The gating of the two PHAs is illustrated schematically in Fig. 2. Gate 1 (the "prompt gate" to the pulse height 
analyzer A) was open during most of the neutron pulse, while high-energy neutrons were striking the target. Gate 2 (the "delayed gate" to PHA B) was opened several tens of microseconds after the beam pulse ended. The delay assured that virtually all high-energy neutrons were absent from the target during the gate. Many neutrons that underwent multiple scattering and thermalized, would still be present in the target and undergoing capture reactions during Gate 2 ; they would tend to diffuse out of the target before the next fast neutron pulse occurred. Gate 2 was shut off well before the next beam pulse to assure that no photons generated by fast neutrons would be recorded in PHA $B$.

Gamma-rays from inelastic scattering events (as well as some prompt photons from particle exchange processes) were recorded only in analyzer A. Gammas from thermal neutron capture were recorded preferentially in PHA $B$; since some thermalized neutrons remained in the sample until the following pulse, however, there was some "leakthrough" of neutron capture gammas into PHA A. Activation products with lifetimes longer than the inter-pulse interval emit gammarays at essentially the same rate during both gates; they populate the spectra in both PHAs in proportion to the two gate lengths.

The rate at which neutrons thermalize and diffuse out of a target sample depends on the size and composition of the sample, particularly on its hydrogen content. Gate 2 was set at a width of approximately half of the inter-pulse interval, and was positioned so that it closed approximately 10 microseconds before the following neutron pulse. The leakthrough of capture gammas into PHA A could have been reduced by operating at lower repetition rates, but dead time and pile-up in the prompt gate would then have increased.

An approximate measure of the capture gamma leakthrough into Gate 1 could be obtained by using a third PHA with a gate the same length as Gate 1 but positioned just prior to 
each neutron pulse (represented as Gate 3 in Fig. 2); it would record approximately the same number and spectrum of capture gamma-rays as Gate 1 , but without the contribution of inelastic gammas. However, this gate was not implemented during the Tooele experiments.

For some samples, delayed spectra (with the neutron generator shut off) were collected following a generator-on run. These neutron-off runs were made to look at gamma-rays from relatively long-lived activation products. Some of these gamma-rays may be useful in identifying key elements, such as arsenic, in the target. Others can give information about background processes which can aid in the data analysis. More experimental details can be found in Reference 6 .

\section{Samples Investigated}

Lewisite (L), sulfur-mustard (HD), and the nerve agents, GB and VX, were examined with the INS system. The atomic compositions of each are summarized in Table I. The $L$ sample was in a steel-walled ton container. The HD samples were in 155-mm artillery rounds, as well as in a ton container. The GB was in 105-mm rounds, an MC-1 bomb, and a ton container. VX was in 155-mm rounds, a spray tank, and M-55 rockets; the latter two munitions had aluminum shells, whereas all other munitions and containers were steel-walled. In addition, we examined a 155-mm white-phosphorous (WP) round, an $\mathrm{MC}-1$ bomb with unknown fill, and a conventional 155-mm artillery round containing high-explosive (Compound B). A summary list of items measured is in Table II $^{7-9}$. 


\section{EXPERIMENTAL RESULTS AND CONCLUSIONS}

\section{A. Identification of Chemical Elements}

Some of the more prominent gamma-rays that were useful for element identification are listed in Table III. Most of these have been identified in HPGe spectra in laboratory experiments at LLNL and/or in measurements on munitions or surrogates at Tooele Army Depot. Some of these lines have only been observed in relatively large target samples. Lines seen by inelastic scattering may also be detectable as activation lines, at exactly the same energies, from $(n, p)$ reactions; a daughter nucleus may beta-decay back to the original nucleus in the same state that is excited by inelastic scattering.

\section{B. Identification of Contents of Munitions and storage Containers}

For the limited set of materials at Tooele Army Depot (with the possible exception of the unknown bomb) the identity of the fill can be inferred from the detected elements according to an algorithm, summarized in Fig. 3.

Table III lists the subset of items at Tooele for which a qualitative analysis has been carried out. Some of the key elemental constituents identified are listed in the table. In some cases, notably chlorine, many additional lines could be identified. Some of the assignments are tentative; further quantitative analysis of the spectra, which are in process, are needed for a positive identification. The above algorithm applied to the elements identified for each item yields a result consistent with the known contents. A typical spectrum for VX, for both prompt and delayed gates, is seen in Fig. 4.

An alternative approach can be used when only the broad category of the fill (i.e., explosive, nerve agent, or blister agent) is required; it is only necessary to measure the relative amounts of oxygen, hydrogen, and carbon in the 
materials. An experimental advantage would be the much shorter times required to obtain data than is required for identifying fluorine, phosphorous, and sulfur. With slightly longer measurement times, the relative amount of nitrogen can also be determined, and somewhat better discrimination obtained. Lewisite can be easily distinguished by this method, and it may even be possible to distinguish Vx from GB. An added advantage of this approach is that the relative amounts of oxygen, hydrogen, carbon, and nitrogen can be measured using a room temperature bismuth germanate (BGO) detector as has been used for the on-line determination of oxygen in coal10, for the determination of body fat in humans11, and suggested for explosives analysis 12 . The separation of various types of $\mathrm{HE}$ and $\mathrm{CW}$ agents is illustrated in Fig. 5. where we compare the gamma spectra from $\mathrm{VX}$ and $\mathrm{HE}$. The actual measurements were 20 minutes long yielding plenty of counts in each peak; we estimate that only 5 minutes are required for this rapid discrimination. Quantitative analysis of oxygen, hydrogen, carbon, and nitrogen by fitting the relevant spectral peaks is required for this approach.

$\mathrm{HE}$ materials, on the basis of their $\mathrm{O} / \mathrm{H} / \mathrm{C} / \mathrm{N}$ ratios, are in fact separable from most common organic materials. The screening approach outlined above is applicable to detecting explosives in a much broader context than $\mathrm{HE}$ and $\mathrm{CW}$ discrimination. Although the separations of other classes of organics may not be as clean as for the HE case, the general method may be useful as an initial fast screening step for other types of materials. 


\section{CONCLUSIONS}

We have described a method for non-destructive evaluation of $\mathrm{CW}$ and $\mathrm{HE}$ using an ion tube neutron souce, which correctly categorized the four chemical agents (GB, VX, $\mathrm{HD}$, and L) as well as $\mathrm{HE}$, and WP in measurements at Tooele. This type of quantitative determination of the chemical ratios, combined with the ability of the high-energy neutrons to excite a wide range of elements, can be applied to the identification of unknown materials in less restrictive scenarios.

\section{ACKNOWLEDGMENTS}

We are indebted to a number of our colleagues at LLNL for assistance in putting together the INS system. We are particularly thankful to John Thorngate for much of the early work with the INS in preliminary experiments which laid the groundwork for the Tooele effort. Ken Dreyer provided the software for controlling the neutron generator and the data acquisition system. We want to acknowledge the Tooele Army Depot and EAI personnel for their outstanding on-site assistance, and Tom Taylor of PNL for his effort in coordinating the exercise.

This work was performed under the auspices of the U.S. Department of Energy by Lawrence Livermore National Laboratory under Contract W-7405-Eng-48.

\section{REFERENCES}

1. "LLNL Explosives Handbook", edited by B. M. Dobratz and P. C. Crawford, Lawrence Livermore National Laboratory, UCRL52997, 1985 .

2."Report of the Conference on Disarmament to the General Assembly of the United Nations", CD/1173, Sept. 1992. 
3 P. Bach, J. L. Ma, D. Froment, and J. C. Jaureguy, Nucl. Instrum. Methods in Phys. Res. B79, (1993) 605.

4. A. J. Caffrey, J. D. Cole, R. J. Greenwood, IEEE

Transactions on Nuclear Science, 39, (1992)1422.

5. E. Rhodes, C. E. Dickerman, A. DeVolpi, C.W. Peters, IEEE Transactions on Nuclear Science, 39, (1992) 1041.

6. R. A. Alvarez and M. R. Rowland, "Neutron Interrogaton to Identify Chemical Elements with and Ion-Tube Neutron Source (INS) at the Tooele Army Depot, August, 1992", in "An Assessment of Nondestructive Testing Technologies for Chemical Weapons Monitoring", T. T. Taylor, ed., Pacific Northwest Laboratory Report PNL-8651(1993)

7. M. A. Lone, R. A. Leavitt, and D. A. Harrison, Atomic Data and Nuclear Data Tables, 26 (1981) 511.

8. K. Randle, J. Radioanal. Nucl. Chem. 72 (1982) 405.

9. Monte Carlo N-Particle Transport Code System (MCNP) Tables, Los Alamos National Laboratory. 1993.

10.G. Vourvopoulos, Nucl. Instrum. and Meth. in Phys. Research B, 56, (1991)917.

11. J. J. Kehayias and H. Zhuang, Nucl. Instrum. Methods in Phys. Research B 79, (1993) 555.

12. G. Vourvopoulos, F. J. Schultz, Nucl. Instrum. Methods in Phys. Research B, 79, (1993) 585. 


\begin{tabular}{|l|c|c|c|c|c|c|c|c|c|c|}
\hline Table I: Atomic Composition of Explosives and Chemical Agents & & \\
\hline & & & & & & & & & \\
\hline Name & Material & C & Cl & P & F & S & As & H/C & O/C & N/C \\
\hline Compound B (HE) & Explosive & 2.03 & 0.00 & 0.00 & 0.00 & 0.00 & 0.00 & 1.30 & 1.32 & 1.07 \\
\hline Sulfur-mustard (HD) & CW Agent & 4.00 & 2.00 & 0.00 & 0.00 & 1.00 & 0.00 & 2.00 & 0.00 & 0.00 \\
\hline Lewisite & CW Agent & 2.00 & 3.00 & 0.00 & 0.00 & 0.00 & 1.00 & 1.00 & 0.00 & 0.00 \\
\hline Sarin (GB) & CW Agent & 4.00 & 0.00 & 1.00 & 1.00 & 0.00 & 0.00 & 2.50 & 0.50 & 0.00 \\
\hline VX & CW Agent & 11.00 & 0.00 & 1.00 & 0.00 & 1.00 & 0.00 & 2.36 & 0.18 & 0.09 \\
\hline
\end{tabular}

\begin{tabular}{|c|c|c|c|c|c|c|}
\hline & Table II: Munitions & and storage & ontainers & neasured & at Tooele Ar & my Depot. \\
\hline \multirow[t]{2}{*}{ Fill } & Container & Elements & & & & \\
\hline & & Present & $\begin{array}{l}\text { Inelastlc } \\
\text { Elements }\end{array}$ & \begin{tabular}{|l} 
Capture \\
Elements
\end{tabular} & \begin{tabular}{|l|} 
Residual \\
Activation
\end{tabular} & Comments \\
\hline $\mathrm{HD}$ & $155 \mathrm{~mm}$ Projectile & $\mathrm{Cl}, \mathrm{S}$ & $S$ & \begin{tabular}{|l} 
Elements \\
$\mathrm{Cl}, \mathrm{S}$ \\
\end{tabular} & & \\
\hline $\mathrm{HD}$ & 1 ton container & $\mathrm{Cl}, \mathrm{S}$ & $\mathrm{S}$ & $\mathrm{Cl}, \mathrm{S}$ & & \\
\hline $\mathrm{v} x$ & spray tank & $P, S$ & $S$ & $P^{*}, S$ & & "Tentative id \\
\hline$G$ & 1ton container & $P, F^{\star}$ & $P, F$ & $\mathrm{P}$ & & "Weak lines, no S observed \\
\hline $\mathbb{B}$ & $105 \mathrm{~mm}$ projectile & $P, F^{*}$ & $P, F$ & & & "Weak lines \\
\hline$L$ & 1 -ton container & $\mathrm{Cl}, \mathrm{As}$ & & a & As & No $S$ observed, Weak $\mathrm{H}$ line \\
\hline HE (Comp. B) & $155 \mathrm{~mm}$ Projectile & $\mathrm{N}$ & $\mathrm{N}$ & & & $\mathrm{H}$ weak \\
\hline WP & $155 \mathrm{~mm}$ Projectile & $P$ & $P$ & & & $\mathrm{H}$ and $\mathrm{O}$ weak \\
\hline
\end{tabular}




\begin{tabular}{|c|c|c|}
\hline \multirow{2}{*}{ Table III: } & \multirow{2}{*}{\multicolumn{2}{|c|}{$\begin{array}{l}\text { Selec }^{*} \text { ed Neutron Capture, Inelastlc Scattering } \\
\text { and Activation Product Gamma-Rays [7-9] }\end{array}$}} \\
\hline & & \\
\hline Element & Type & Energy (keV) \\
\hline \multirow[t]{2}{*}{$\mathrm{F}$} & inelastic & $197,1240,1357$ \\
\hline & activation & 197 \\
\hline \multirow[t]{3}{*}{$P$} & capture & $636,2154,3900,6785$ \\
\hline & inelastic & 1266,2234 \\
\hline & activation & 1779 \\
\hline S & capture & $841,2380,5421$ \\
\hline \multirow[t]{3}{*}{ a } & inelastic & 2230 \\
\hline & capture & $517,788,1165,1601,1951,1959,5715$, \\
\hline & & $6111,6620,7414,7790$ \\
\hline \multirow[t]{3}{*}{ As } & capture & 6736,7368 \\
\hline & inelastic & 560,570 \\
\hline & activation & $559,596,635$ \\
\hline $\mathrm{H}$ & capture & 2223 \\
\hline 0 & inelastic & 6130 \\
\hline C & inelasic & 4439 \\
\hline \multirow[t]{2}{*}{$N$} & capture & $1885,5269,5298,5533,6322,10829$ \\
\hline & inelastic & $1632,2313,5106,7028$ \\
\hline \multirow[t]{2}{*}{$\mathrm{Fe}$} & capture & $352,1725,5920,6018,7631,7645,9298$ \\
\hline & inelastic & 1238 \\
\hline \multirow[t]{2}{*}{ Al } & capture & $1779,4133,4260,4734,7724$ \\
\hline & inelastic & $843,1013,1719,2210$ \\
\hline \multirow[t]{2}{*}{$\mathrm{Si}$} & capture & $2093,3539,4934,6381,7201$ \\
\hline & inelastic & 1779,2210 \\
\hline \multirow[t]{2}{*}{$\mathrm{Pb}$} & capture & 6736,7367 \\
\hline & activation & 569,1063 \\
\hline $\mathrm{B}$ & capture & 478 \\
\hline \multirow[t]{2}{*}{ Ge } & capture & $175,596,868,3028$ \\
\hline & inelastic & 596,693 \\
\hline
\end{tabular}




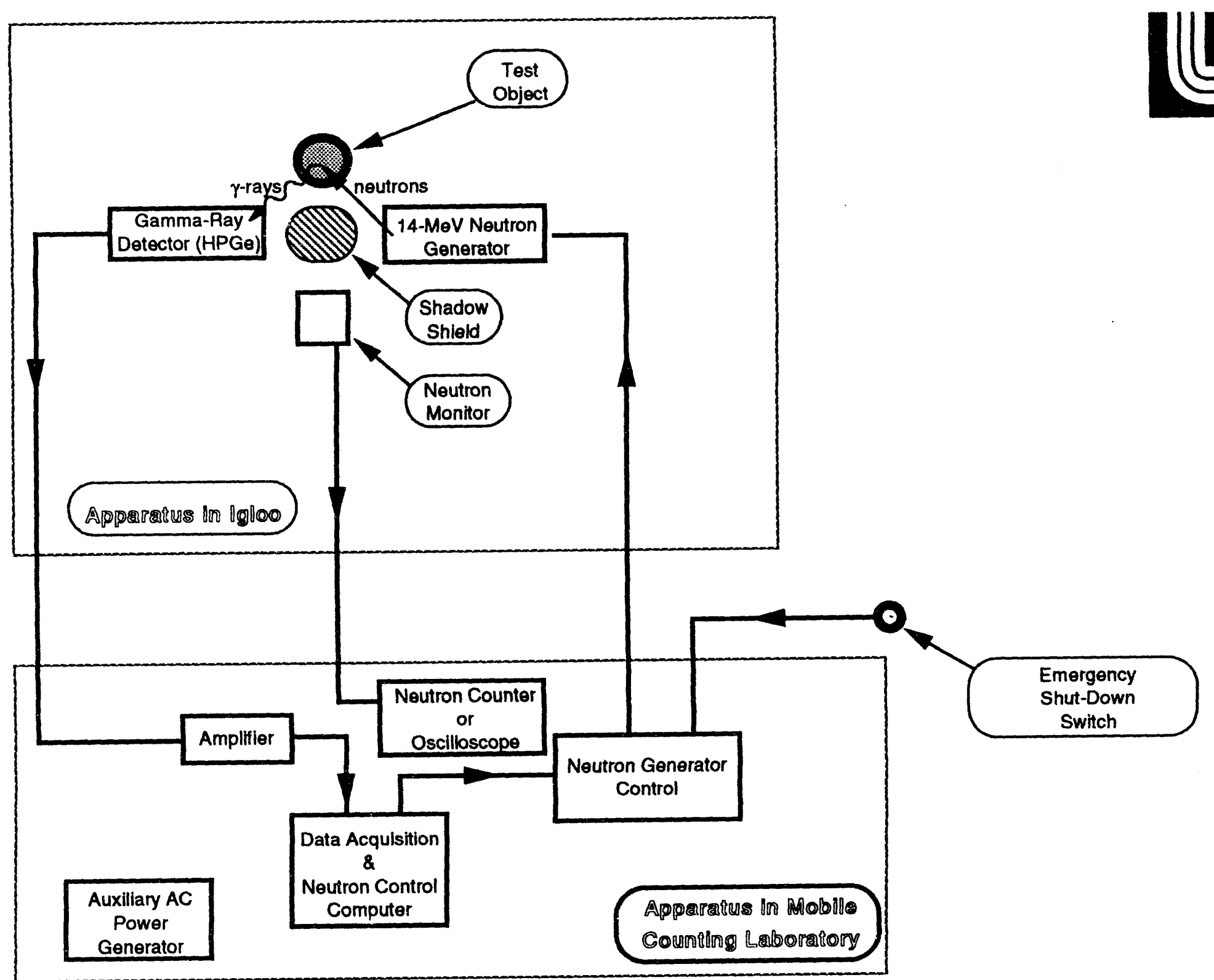

Fig. 1

Simplified Block Diagram of Apparat: 


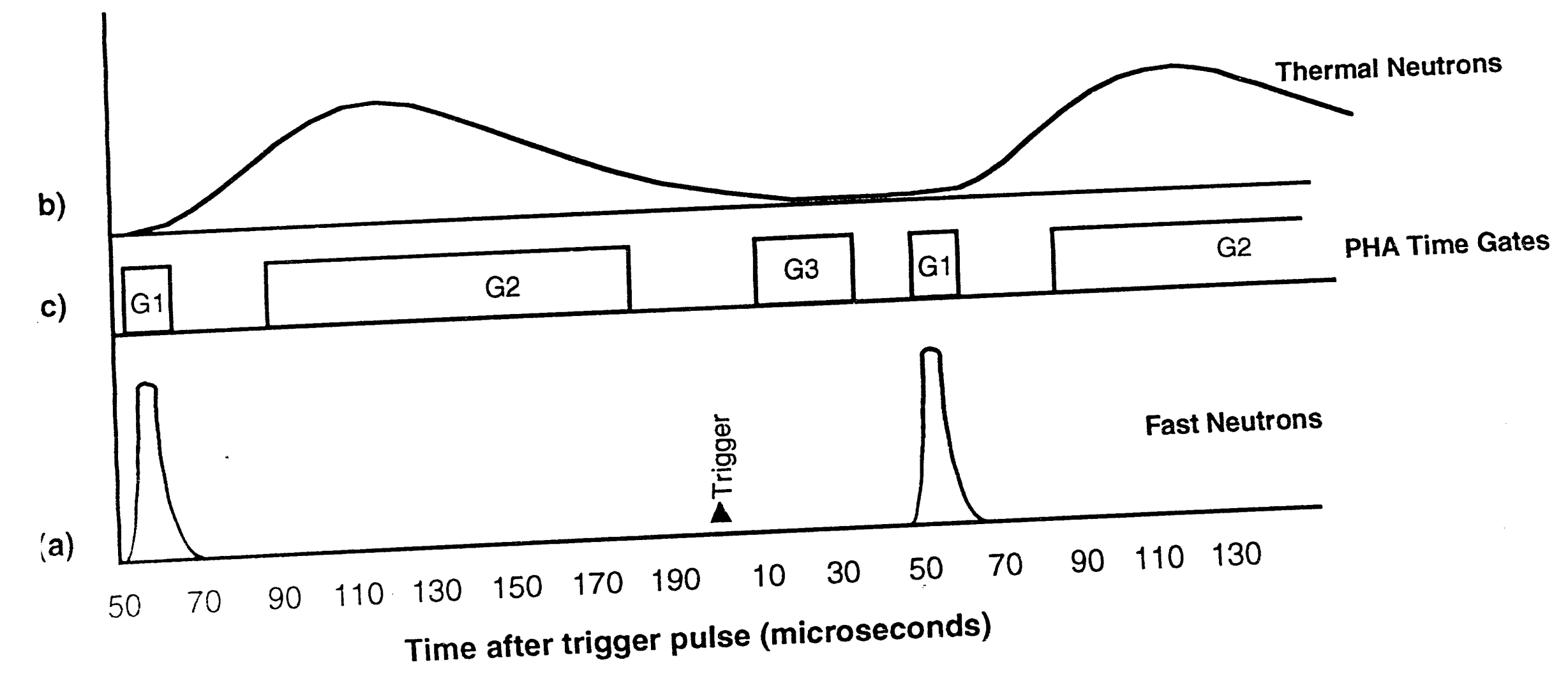

Primarily inelastic scattering events, with small capture background

i... Primarily thermal capture and delayed activation events

sproximates capture ä delayed activation background in $\mathrm{G} 1$.

Fin. 2: Neutron Flux Timing and Gates 
Fig. 3: Decision Tree

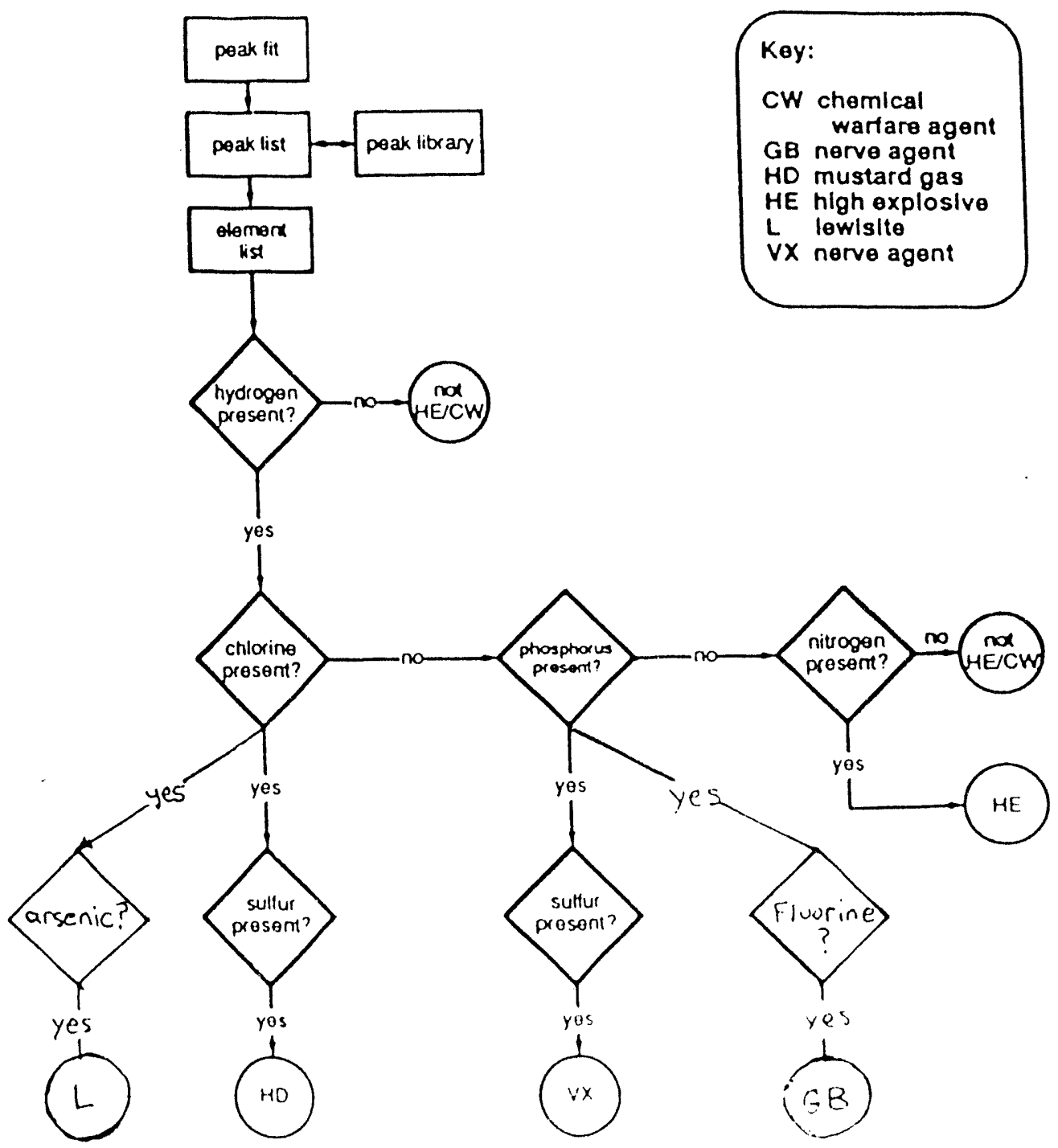




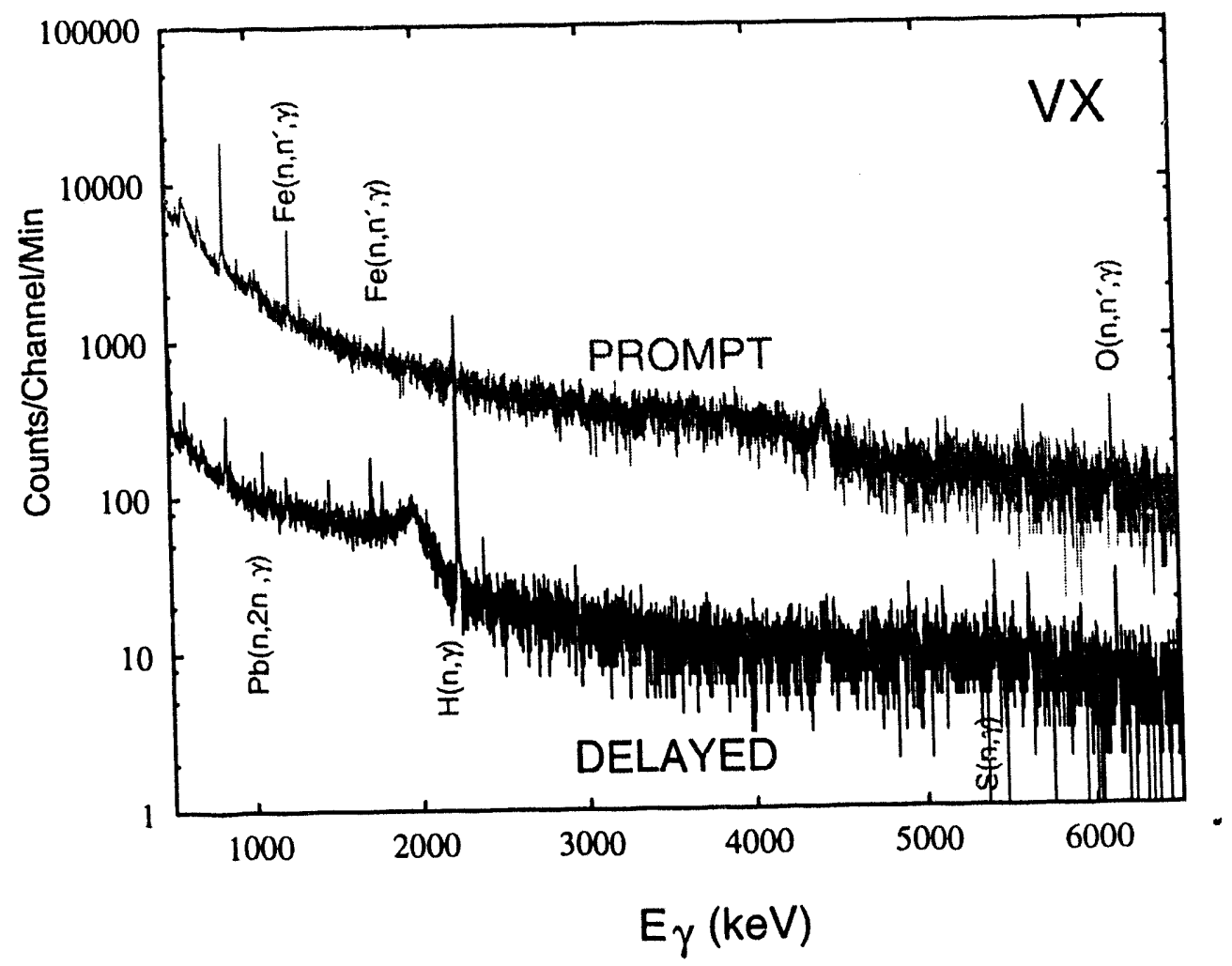

Fig. 4. Gamma-ray spectra of VX in the prompt gate (upper) and delayed gate (lower).

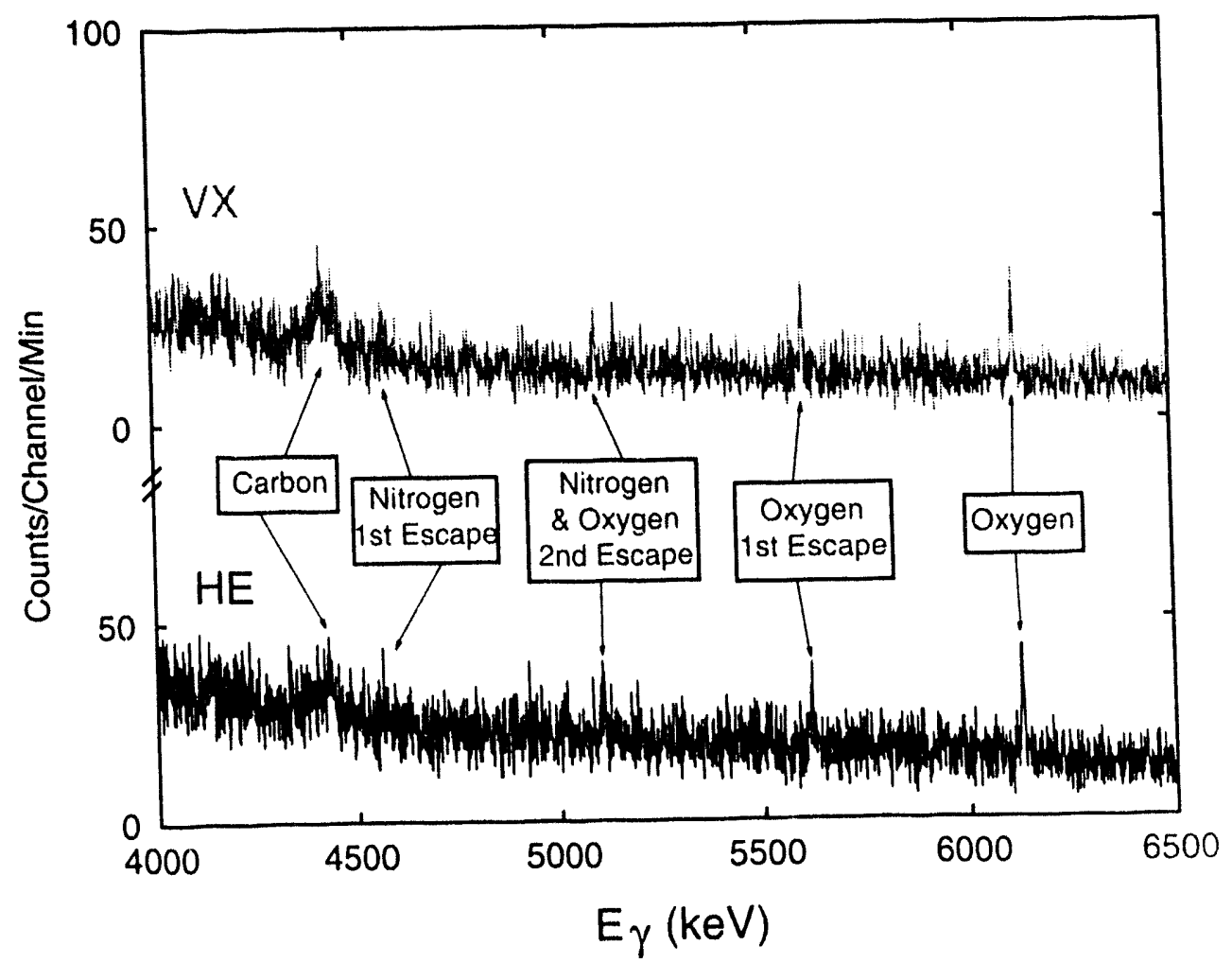

Fig. 5. Comparison of gamma-ray spectra of $\%$ and $h:$, showing relative intensities of carbon, oxygen, and nitrogen. 

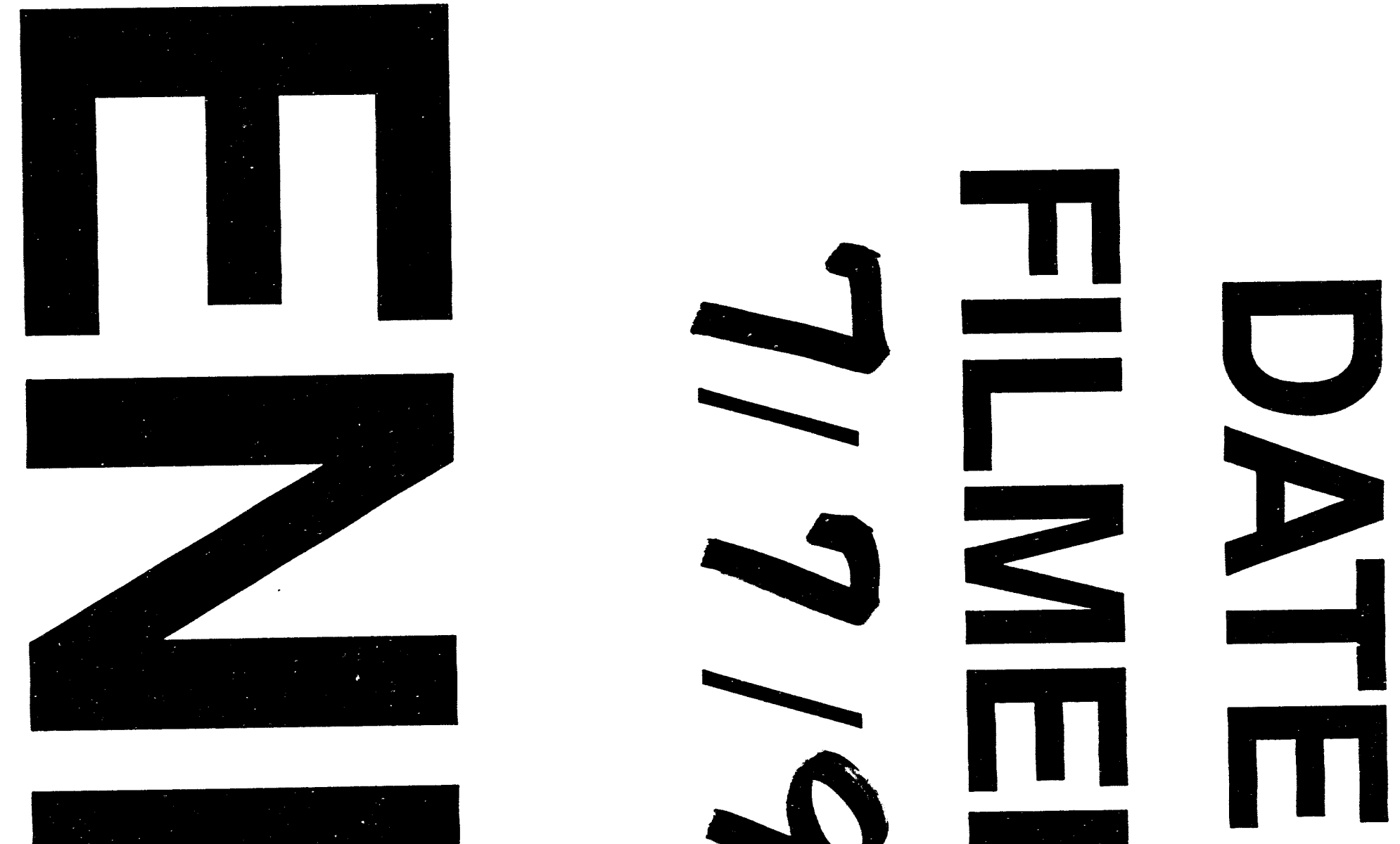

5
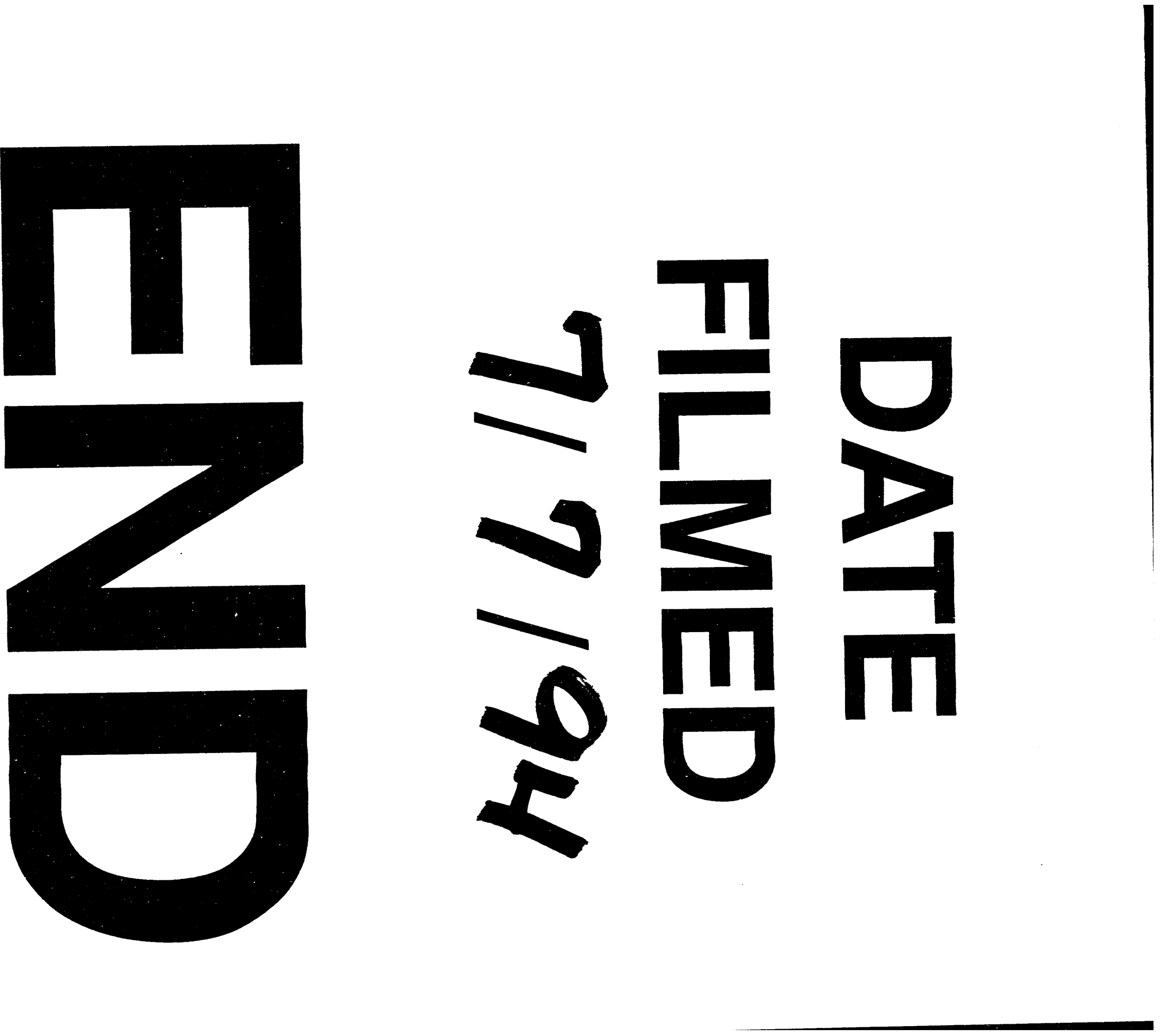
